\title{
Team-Based Learning Student Assessment Instrument (TBL-SAI) for measuring the effectiveness of TBL in a Saudi Medical School: Psychometric Analysis and differences by academic years
}

Mutasim E Ibrahim ( $\square$ mutasimhadi87@hotmail.com )

College of Medicine, University of Bisha, KSA

\section{Research article}

Keywords: Team-based learning, applicability, medical students, psychometrics, Saudi Arabia

Posted Date: June 24th, 2019

DOl: https://doi.org/10.21203/rs.2.10577/v1

License: @ (i) This work is licensed under a Creative Commons Attribution 4.0 International License. Read Full License 


\section{Abstract}

Background Increasing the use of Team Based Learning (TBL) in health profession education reinforce the need to develop a proper instrument for measuring the applicability of this method. This study aimed to examine the psychometric properties of TBL-SAI and the mean score of instrument subscales by the different academic year of the students. Methods Across-sectional study was conducted at the University of Bisha, College of Medicine (UBCOM), Saudi Arabia. Medical students from second to fourth were included in the study. Participants were completed the TBL-SAl items to measure three subscales of accountability, preference for a lecture or TBL and satisfaction. Cronbach's alpha, factor analysis, were checked the reliability and validity of the instrument. A principal component analysis (PCA) with varimax rotation was conducted on each subscale. ANOVA analyzed the TBL effectiveness related to the different years of medical school. Results Cronbach's alpha was 0.798 and factor loading was greater than 0.40 for all the items, indicating the reliability and validity of the scale. In a PCA, accountability items generated two factors with loading $>0.40$, except items one and four. All preference and satisfaction items have factors loading $>0.40$. Fourth-year students' obtained significant highest mean scores for accountability $(p=0.0 .49)$, preferences $(p=0.001)$ and satisfaction $(p<0.001)$ compared to third and second years students. Conclusions TBL-SAl is a sound tool to measure the favor of TBL among medical students. Longitudinal studies are recommended to bring a clear picture of the effectiveness of TBL in UBCOM.

\section{Background}

Team-based learning (TBL) has become an increasingly important educational method of a medical curriculum in the last few years [1,2]. It was first introduced by Larry Michaelsen in 1970 within the field of business education [3,4]. Later, TBL found to be suitable for health profession education because of its relevancy as a student-centered learning philosophy [4]. The primary principles of TBL are to improve students' skills on problem-solving, critical thinking, communication and teamwork by employing multiple groups in a large class setting $[5,6]$. Well-known that TBL is an ideal education strategy stress higher-order thinking and help in applying scientific contents in further clinical environments [7,8]. Performing TBL strategy needs three specific steps, including advance homework before their class, readiness assurance tests to assess understanding of the pre-class materials followed by application of learning materials in a clinicalcontext scenario $[2,9]$.

Considerable research has assessed the value and effectiveness of TBL as a pedagogical approach $[8,10,11]$. According to Taglieri et al. although TBL is thought to improve student engagement and mastery of material, after initial implementation of TBL, knowledge retention in the long-term appears to be lower than lecture-based learning [12]. In a randomized crossover comparison study of TBL and lecture format, Bleske et al. found that learning outcomes and student confidence in performing higher-order tasks were significantly higher with TBL [11]. On the other hand, a study found that blending of TBL and lecture-based learning strategy lead to better learning outcomes than either method alone in neurology clerkships [9]. Increasing the numbers of research on TBL pedagogy with different opinions reinforce the need for developing a sound instrument for measuring the effectiveness of this learning approach [13]. So far, there are limited validated instruments to assess students opinion about major areas of TBL approach $[13,14]$ The team-based learning student assessment instrument (TBL-SAI) has been developed for measuring accountability, learning preference and students' satisfaction with TBL [15]. The psychometric properties of TBL-SAl have been confirmed in several health profession educations across different countries $[4,13-16]$.

The medical program at the University of Bisha, College of Medicine (UBCOM) is a hybrid PBL approach blended with a minimum number of traditional lectures and different types of student-centered activities as well as TBL. Both of TBL and lecture are part of the teaching method across all modules of basic sciences, preclinical and clinical phases [17]. Some medical schools in Saudi Arabia use TBL strategy in their undergraduate curricula [17-19]. However, the applicability of TBLI-SAI has not yet been examined among medical school in the country. Currently, studies about the effectiveness of TBL in Saudi Arabia remains limited and many dimensions of TBL did not study. For instances, a study conducted at the College of Medicine at Alfaisal University to assess first-year medical students' perceptions about TBL on three major domains of reaction, learning, and behavior based on Kirkpatrick's theory [20]. Another study found that TBL strategy increased students responsibility for self-learning, and improved their academic performance in the neurosciences block [18].

The present study was designed to examine the validity and reliability of TBL-SAl in a sample of medical students at UBCOM. The study also aimed to assess TBL attitudes in terms of accountability, preference, and satisfaction among second to third years medical students. 


\section{Methods \\ Study design and setting}

Across-sectional study was conducted among medical students at UBCOM, Bisha, Saudi Arabia, which admits about $40 \pm 5$ medical students each year to a six-year MBBS program. Medical curriculum in UBCOM arranged into modules that extend through the three phases of basic medical science (year two and three), pre-clerkship (year four) and clerkship (year five and six). Each academic year consists of two semesters that divided into course modules. TBL, problem-based learning, lectures and other types of students centered activities offered to deliver the contents of modules [21].

\section{Study subjects}

Medical students at second, third and fourth years who matriculated for the academic year 2017-2018 were included in the study. Participation in the study was voluntary and approved by the ethics and research committee at UBCOM.

\section{Conduction of TBL in UBCOM}

UBCOM offers the TBL method during the three phases of the curriculum that arranged into modules that extend from two to ten weeks. One TBL session introduced every week, and the number of the sessions depends on the module duration. The session carried out through three essential steps of pre-class preparation, redness and assurance and application [17]. First, before the class session, the students completed a self-directed study of a selected learning material guided by specific learning objectives of the topic. For this first step, a two-to-four hour scheduled in a weekly course timetable and assigned for self-directed-learning for the TBL preparation. Second, 100 minutes class session conducted in the classroom where the students assigned to a team comprised of 7 to 10 members. Students remain in their assigned teams during the course to become more effective in helping members master and apply course content. A content expert joined as a facilitator to directs the discussions and provides educational expertise for the students. Ten multiple-choice questions (MCQs) for 15 minutes taken by each student as an individual readiness assurance test (iRAT) at the beginning of the session. Then, immediately the same ten MCQs repeated by students as a group (group readiness assurance test; gRAT) for 30 minutes, with the intent of promoting discussion to prove group consensus on one answer for each question. MCQs and expected answers were reviewed in the classroom so the facilitator can correct any wrong assumptions and confirm the important learning concepts. The primary purpose of iRAT and gRAT were to measure the level of students readiness for the class session. Third, students work into their groups to apply the gained concepts through solves a challenging clinical scenario or case problems created in MCQs format. The scores existed from iRAT, gRAT and application exercise contributed in students course grade. Such scoring has been applied to increase students attendance and participation in the class.

\section{Instrument description}

The permission to use TBL-SAI was granted by Heidi Mennenga. The TBL-SAI scale originally developed for assessing TBL in baccalaureate nursing students [15] and was found to be reliable among medical students $[4,16]$ and other health profession students $[13,14]$. The psychometric properties of the TBL-SAI scale have been reported as satisfactory, and the construct validity of the scale has been examined previously elsewhere $[13,15]$. The instrument is a self-administrated contains 33 items (with total scores ranging from 33165) designed to measure students' attitude toward TBL. It composed of three subscales to measure TBL accountability (items 1 to 8 , with scores ranging from 8-40), preference for lecture or TBL (items 9 to 24 with scores ranging from 16-80) and students satisfaction (items 25 to 33 with scores ranging 9-45). Positive perception about the use of TBL pointed out by score of $>99$ for the total scale, $>24$ for accountability subscale, $>48$ for preference for TBL over lecture subscale and > 27 for students satisfaction subscale [15].

\section{Sampling procedure}

The purpose of the study was explained to the participants before the data sampling. Participating in the study was anonymous and voluntary, with no influence on the progress of their educations was clearly stated for the students. The TBL-SAl items translated into Arabic for a better understanding of difficult items and printed copies containing both English and Arabic delivered to the students. The 
questionnaire forms fully completed by the target medical students during class time and in the presence of the principal investigator to clarify any queries or doubts. Whereas students absent during the survey were excluded from the study. The students asked to answer on a five-point Likert scale which scored from 1, 2, 3, 4, 5 as disagree, disagree, neutral, agree, or strongly agree, respectively. Among the 33 items, 10 negatively worded items in the scale were reverse scored by assigning 5, 4, 3, 2, or 1 [15].

\section{Statistical analysis}

Data entry and analysis were subjected to ISBN SPSS version 20 with 0.05 as a significant value. Simple descriptive statistics were used to generate the result data in percentages, mean, and standard deviations. Significant correlations between variables were measured using Bartlett's test of sphericity. Kaiser-Meyer-Olkin test (KMO) was performed for the whole instrument items for measuring sampling adequacy. Values higher than 0.60 for the total items indicate that factor analysis can be conducted [13]. A principal component analysis with varimax rotation was conducted on each subscale of TBL-SAl to identify the underlying factor structure. Extraction of factors was determined by consideration of eigenvalues greater than 1 and examination of the scree plot. Items with factor-loading values greater than 0.40 were valid within the instrument and required for interpreting the factor structure $[13,15]$. Internal consistency and reliability of the instrument were analyzed using Cronbach's alpha, with a greater value of 0.70 and higher is acceptable [15]. Oneway analyses of variance (ANOVA) was analyzed the differences in TBL effectiveness related to the different years of medical school.

\section{Results}

\section{Demographic characteristics}

One hundred twenty-three male Saudi medical students from year two, three and four were involved in the study. Of the total number of students, $90.1 \%$ (109) were attended the class sessions and completely responded to the questionnaires. Of these, 100\% (31/31) from year four, $81.8 \%$ (36/44) from year three, 87.5\% (42/48) from year two. These participants within the age of 18 to 22 years old.

\section{Reliability and validity of the instrument}

Cronbach's alpha coefficient was 0.798 for the total instrument items; 0.771 for year two, 0.760 for year three, 0.742 for year four. All items had a factor loading of greater than 0.40 , indicating the validity of the scale.

\section{Principal component analysis of the total scale}

The Kaiser-Meyer-Olkin Measure of Sampling Adequacy yielded an index of 0.737, and Bartlett's test of sphericity gave Chi-Square (528) $=1701.425 ; p<0.001)$; indicate the appropriateness of the data for PCA.

\section{Accountability subscale}

The Kaiser-Meyer-Olkin Measure of Sampling Adequacy yielded an index of 0.796, Bartlett's test of sphericity gave Chi-Square (28) = 200.351; $p<0.001)$. Two factors were generated the subscales accountability that accounted for $53.3 \%$ of the total variances. Questions 8, 6,2,7 and 5 loaded on factor 1, whereas Question 3 loaded on factor 2. Questions 1 and 4, had factor loadings of less than 0.40 (Table 1).

\section{Preference subscale}

The Kaiser-Meyer-Olkin Measure of Sampling Adequacy yielded an index of 0.719, and Bartlett's test of sphericity gave Chi-Square (120) $=511.711 ; p<0.001)$. Four factors were generated from the subscales TBL preference that accounted for $57.9 \%$ of the total variances. Factor 1, and 3 consisted of 8 items labeled as TBL. Factor 2 and 4 consisted of six items labeled as a lecture (Table 2).

\section{Satisfaction subscale}


The Kaiser-Meyer-Olkin Measure of Sampling Adequacy yielded an index of 0.832, and Bartlett's test of sphericity gave Chi-Square (36) = $379.891 ; p<0.001)$. Two factors were generated the subscales satisfaction that accounted for $59.5 \%$ of the total variances (Table 3 ).

\section{Comparison of data set}

Table 4 summarizes the total instrument score and three subscales scores for the students from different academic levels. The mean total score for TBL-SAl was $111.6(S D=15.4)$. The mean score for the entire subscale was $28.4(S D=5.5)$ for accountability, $51.7(S D=7.3)$ for TBL preference and 31.5 ( $S D=6.3$ ) for satisfaction. Fourth-year students' obtained significant highest mean scores for accountability $(p=0.0 .49)$, preferences $(p=0.001)$ and satisfaction $(p<0.001)$ compared with the students in year three and year two.

\section{Discussion}

The purpose of this study was to describe the psychometric properties of TBL-SAl and its implementation in a medical school. To best of our knowledge, this was the first study examining attitudes of medical students toward TBL in Saudi Arabia using TBL-SAI. The internal consistency of the total scales was 0.798 , and all items showed a factor loading of greater than 0.4 . These results support the validity and reliability of the instrument to measure the effectiveness of TBL pedagogy in medical students in Saudi Arabian medical schools context. Other authors have examined the appropriateness of the TBL-SAI scale and found to be valid [13,16,22]. Overall, the mean score for TBL-SAl in this study was favorable (111.6), when compared with the reference values proved by Mennenga [15]. However, scores obtained from this study was lower than 159.68 rated by medical students [4], 117.9 rated by pharmacy students [13] and 115.6 to 125.3 rated by Physical therapy students [14]. A possible reason for our findings could be attributed to the short experience of TBL since UBCOM was established in 2014. Thus, long terms of experience with TBL may perhaps increase students respect to such educational method.

Principal analysis of accountability items in this study resulted in two underlying factors concern students' contribution to the team and well preparation of learning topic before TBL session. Students' accountability displayed by the commitment to the attendance of TBL sessions, class preparation, increased motivation to class preparation and effective participation in their groups. In this study, medical students had high scores toward accountability subscale. A previous study supporting the power of TBL-SAl instrument to measure students accountability in Iran [4] and the United State [14]. It has widely accepted the keys aspects for effective TBL accountability should include an emphasis on improving students' pre-reading, self-direct learning and teamwork skill $[16,23,24]$. Interestingly, our results showed that items 1 ("I spend time studying before class in order to be more prepared") and 4 ("My contribution to the team is not important") yielded low factor loading (less than 0.4). However, a decreased factor loading value for item 4 has been found in a study carried out among Pharmacy students in the United Kingdom [13].

The preference for TBL or lecture methods indicates the student's ability to recall material and their degree of attention with one learning methods [14]. Our result showed that all the items of subscale assessing students' preference for TBL or lecture attained loadings of higher than 0.40. However, four factors were extracted and labeled as "TBL; factor 2 and 4" and "Lecture; factor 1 and 3". Several studies compared the learning outcomes of TBL to the lecture, and most of them found that TBL yielded better academic results [4,25-27]. In a study comparing learning outcomes and student confidence between TBL and lecture, Bleske et al. found that student confidence in performing higher-order tasks was significantly higher with TBL, and a majority of students preferred TBL pedagogy to lecture format [11]. However, other authors reported a neutral score of students regarding preference of TBL against traditional lecture [22]. Several factors could influence the students' opinion between TBL or lecture, such as the timing of TBL introduction, the subject matter to be taught by TBL, experience of facilitators and module contents [22]. Therefore, proper organization of course contents, ground conditions in the classroom and appropriate selection of the learning materials for the TBL sessions can lead to a positive attitude toward this instructional strategy.

Since UBCOM is using TBL as instructional method during the three phases of the medical curriculum, more research should be carried out to understand the long-term impact of TBL across the different academic years. In our samples, two factors were extracted on the student satisfaction subscale, indicating that our students have positive feelings toward TBL activities. Moreover, students satisfaction with TBL strategy have been documented in the literature $[16,28]$ It has been noted that the quality and effectiveness of the learning process were associated with TBL satisfaction. According to Roh et al. (2014), five instructional design factors including, learning process, pre-assignment, course content, peer evaluation, and team activity - significantly influenced learner satisfaction, with learning process exerting the largest influence [23]. 
Comparing TBL attitudes among medical students, there were significant differences in students mean responses according to the academic level. Generally, fourth-year students obtained a higher mean score for the three subscales compared with second and thirdyear students. This fit with the fact that long-term use of TBL in the education system improves the impact of this assay [16]. Contrary to expectations, third-year students achieved lower insignificant mean score compared to the second year students. This does not reflect the theory of that TBL becomes an enjoyable and valuable learning tool, and students respond positively after experienced it. TBL favor increased after students learning experience with TBL [3]. This phenomenon could be a result of motivational variations between year two and year three students. As mentioned in the literature, students have unfavorable opinions of TBL because of its extensive needs of out-of-class preparation, workload and class participation [12]. Furthermore, evidence suggests that learning styles and personality types of students are significant factors influencing learning that takes place in a small-group TBL setting [29]. Another possible explanation is that learning materials selected for TBL activities might not be well prepared or inappropriate to introduce via such pedagogy. The reasons for this could be identified by conducting a focused group discussion among students those are not like TBL method.

\section{Limitations of study}

The study addresses the following limitations that should keep under consideration. The main limitation of the study was sample size although the study targeted all medical students enrolled in UBCOM. Several recommendations reported in the literature about the proper sample size to use for conducting a factor analysis. It was widely accepted that larger sample size is better for factor analysis that provides expected measures [30]. The study did not involve medical students at year five and six since UBCOM did not matriculate students in these years when the study was conducted. In future investigations, it might be possible to include all medical students from year two to six to get a wide picture of TBL in our medical school. Skillful facilitator of TBL has ability creates a right learning environment and engaging reluctant students. In general, this might succeed by the ability to manage the session time, actively listen, paraphrase, summarize and draw out the answers from the students, support students accountability[2]. However, many of the facilitators in UBCOM were a novice in the implementation of TBL that might cause a negative attitude among students toward TBL.

\section{Conclusions}

In conclusion, the findings of the present study provide evidence for the reliability of TBL-SAI and supporting the validity of this instrument for medical students. Our students rated a positive score for TBL favor despite was lowest when compared with those reported in other studies. Overall, our experience with TBL is promising in terms of accountability, preference for learning mode, and students' satisfaction. Medical students in year four have more admiration for the TBL method than second and third-year students. This confirms that long-term use of TBL in the education system improves the impact of this method on students. Moreover, further longitudinal studies are recommended to bring a clear picture of the effectiveness of TBL in UBCOM.

\section{Abbreviations}

ANOVA: One-Way Analyses Of Variance; gRAT: Group Readiness Assurance Test; iRAT: Individual Readiness Assurance Test; KMO: Kaiser-Meyer-Olkin test; MCQs: Multiple-Choice Questions; PCA: Principal Component Analysis; SD: Standard Deviation; TBL-SAI: TeamBased Learning Student Assessment Instrument; UBCOM: University of Bisha, College of Medicine.

\section{Declarations}

\section{Ethics approval and consent to participate}

The Ethics and Research Committee at the University of Bisha, College of Medicine approved the study protocol (meeting number 0217/18). Informed written and oral consent was obtained from all participants prior to participation in the study.

\section{Consent for publication}

Not applicable. 


\section{Availability of data and materials}

No data has been submitted to any open-access databases. All data supporting the study are presented in the manuscript or are available upon request.

\section{Competing interests}

The author declares that they have no competing interests.

\section{Funding}

The authors have no funding to declare.

\section{Authors' contributions}

The author alone is responsible for the content and writing of the article.

\section{Acknowledgments}

I would like to appreciate the contribution of the students in Unoversity of Bisha, College of Medicine in this study.

\section{References}

1. Burgess AW, McGregor DM, Mellis CM. Applying established guidelines to team-based learning programs in medical schools: A systematic review. Acad Med. 2014;89:678-88.

2. Gullo C, Ha TAMCAM, Cook S. Twelve tips for facilitating team-based learning. Med Teach. 2015;37:819-24.

3. Eksteen MJ, Reitsma GM, Swart SB, Fourie E. Team-Based Learning Experiences of Fourth-Year Pharmacy Students in a South African University. Am J Pharm Educ. 2018;82.

4. Faezi ST, Moradi K, Ghafar Rahimi Amin A, Akhlaghi M, Keshmiri F. The effects of team-based learning on learning outcomes in a course of rheumatology. J Adv Med Educ Prof. 2018;6:22-30.

5. Bleske BE, Remington TL, Wells TD, Dorsch MP, Guthrie SK, Stumpf JL, et al. Team-Based Learning to Improve Learning Outcomes in a Therapeutics Course Sequence. Am J Pharm Educ. 2014;78:1-5.

6. Park H-R, Kim C-J, Park J-W, Park E. Effects of team-based learning on perceived teamwork and academic performance in a health assessment subject. Collegian. Australia; 2015;22:299-305.

7. Gryka R, Kiersma ME, Frame TR, Cailor SM, Chen AMH. Comparison of student con fi dence and perceptions of biochemistry concepts using a team-based learning versus traditional lecture- based format. Curr Pharm Teach Learn. Elsevier; 2017;9:302-10.

8. Remington TL, Bleske BE, Bartholomew T, Dorsch MP, Guthrie SK, Klein KC, et al. Qualitative Analysis of Student Perceptions Comparing Team-based Learning and Traditional Lecture in a Pharmacotherapeutics Course. Am J Pharm Educ. 2017;81.

9. Yang L, Jiang L, Xu B, Liu S, Liang Y, Ye J, et al. learning methods for neurology clerkship in China: a method-comparison study. BMC Med Educ. 2014;14.

10. Behling KC, Murphy MM, Lopez OJ. Team-Based Learning in a Pipeline Course in Medical Microbiology for Under-Represented Student Populations in Medicine Improves Learning of Microbiology Concepts. J Microbiol Biol Educ. 2016;17:370-9. 
11. Bleske BE, Remington TL, Wells TD, Klein KC, Guthrie SK, Tingen JM, et al. A Randomized Crossover Comparison of Team-based Learning and Lecture Format on Learning Outcomes. Am J Pharm Educ. 2016;80:1-5.

12. Taglieri C, Schnee D, Dvorkin L, Zaiken K, Mistry A, Nigro S, et al. Comparison of long-term knowledge retention in lecture-based versus fl ipped team-based learning course delivery. Curr Pharm Teach Learn. Elsevier; 2017;9:391-7.

13. Nation LM, Tweddell S, Rutter $P$. The applicability of a validated team-based learning student assessment instrument to assess United Kingdom pharmacy students ' attitude toward team-based learning. J Educ Eval Health Prof. 2016;13.

14. Livingston B, Lundy M, Harrington S. Physical therapy students ' perceptions of team-based learning in gross anatomy using the Team-Based Learning Student Assessment Instrument. J Educ Eval Health Prof. 2014;11.

15. Mennenga HA. Development and Psychometric Testing of the Team-Based Learning Student Assessment Instrument. Nurse Educ. 2012;37:168-72.

16. Keshmiri F, Rahmati A, Amin AG, Faezi T. Validating and Assessing the Reaction of Medical Students Toward Team-Based Learning. Acta Med Iran. 2016;54:806-11.

17. Ibrahim ME, Al-shahrani AM. Implementing of a problem-based learning strategy in a Saudi medical school: requisites and challenges. Int J Med Educ. 2018;9:83-5.

18. Anwar K, Shaikh AA, Sajid MR, Cahusac P, Alarifi NA, Shedoukhy A Al. Medical Education Online. 2015;1:1-6.

19. Sharaf F, Alnohair S. Comparison of medical students ' learning approaches between electronic and hard copy team-based learning. Int J Health Sci (Qassim). 2017;11.

20. Obad AS, Peeran AA, Shareef MA, Alsheikh WJ, Kalagi DA, Alamodi AA, et al. Assessment of first-year medical students ' perceptions of teaching and learning through team-based learning sessions. Adv Physiol Educ. 2016;40:536-42.

21. Ibrahim ME, Al-Shahrani AM, Abdalla ME, Abubaker IM, Mohamed ME. The Effectiveness of Problem-based Learning in Acquisition of Knowledge, Soft Skills During Basic and Preclinical Sciences: Medical Students ' Points of View. Acta Inf Med. 2018;26:119-24.

22. Corbridge SJ, Corbridge T, Tiffen J, Carlucci M. Implementing Team-Based Learning in a Nurse Practitioner Curriculum. Nurse Educ. 2013;38:202-5.

23. Roh YS, Lee SJ, Mennenga $\mathrm{H}$. Factors influencing learner satisfaction with team-based learning among nursing students. Nurs Health Sci. Australia; 2014;16:490-7.

24. Kazory A, Zaidi Z. Team-Based Learning Activities for First-Year Medical Students: Perception of the Learners. South Med J. United States; 2018;111:525-9.

25. Vasan NS, Defouw DO, Holland BK. Modified Use of Team-Based Learning for Effective Delivery of Medical Gross Anatomy and Embryology. Anat Sci Educ. 2008;1:3-9.

26. Inuwa IM. Perceptions and Attitudes of First-Year Medical Students on a Modified Team-Based Learning (TBL) Strategy in Anatomy. Sultan Qaboos Univ Med J. 2012;12:336-43.

27. Reimschisel T, Herring AL, Huang J, Minor TJ, Reimschisel T, Herring AL, et al. A systematic review of the published literature on teambased learning in health professions education. Med Teach. 2017;39:1227-37.

28. Reinig BA, Horowitz I, Whittenburg GE. The Effect of Team-Based Learning on Student Attitudes and Satisfaction. J Innov Educ. 2011;9:27-47.

29. Frame TR, Cailor SM, Gryka RJ, Chen AM, Kiersma ME, Sheppard L. Student Perceptions of Team-based Learning vs Traditional Lecture-based Learning. Am J ofPharmaceutical Educ. 2015;79.

30. Mundfrom DJ, Shaw DG, Ke TL, Mundfrom DJ, Shaw DG, Lu T, et al. Minimum Sample Size Recommendations for Conducting Factor Analyses Minimum Sample Size Recommendations for Conducting Factor Analyses. Int J Test. 2009;5:159-68.

Page $8 / 11$ 
Table 1: Factor Loadings, mean and SD, and communalities (h2) for principal components analysis with Varimax rotation on the 8 items of Accountability Subscale

\begin{tabular}{|l|c|c|c|c|}
\hline Item & $\begin{array}{c}\text { Factor } \\
\mathbf{1}\end{array}$ & $\begin{array}{c}\text { Factor } \\
\mathbf{2}\end{array}$ & $\begin{array}{c}\text { Mean } \\
\text { (SD) }\end{array}$ & Communalities $\mathbf{h 2}$ \\
\hline Q8. I need to contribute to the team's learning. & $\mathbf{0 . 8 2 0}$ & 0.014 & $3.6(1.2)$ & 0.673 \\
\hline Q6. I am accountable for my team's learning. & $\mathbf{0 . 7 7 8}$ & 0.188 & $3.7(1.2)$ & 0.640 \\
\hline Q7. I am proud of my ability to assist my team in their learning. & $\mathbf{0 . 7 0 6}$ & 0.199 & $3.6(1.3)$ & 0.538 \\
\hline Q2. I feel I have to prepare for this class in order to do well. & $\mathbf{0 . 6 6 2}$ & 0.002 & $4.1(1.2)$ & 0.435 \\
\hline Q5. My team members expect me to assist them in their learning. & $\mathbf{0 . 6 2 0}$ & 0.258 & $3.4(1.2)$ & 0.451 \\
\hline $\begin{array}{l}\text { Q1. I spend time studying before class in order to be more } \\
\text { prepared. }\end{array}$ & 0.312 & 0.227 & $3.6(1.1)$ & 0.149 \\
\hline Q4. My contribution to the team is not important. & 0.063 & -0.911 & $2.8(1.5)$ & 0.835 \\
\hline Q3. I contribute to my team members' learning. & $\mathbf{0 . 4 0 3}$ & $\mathbf{0 . 6 1 2}$ & $3.7(1.3)$ & 0.537 \\
\hline Eigenvalue & 3.16 & 1.1 & & \\
\hline \% of variance & 39.5 & 13.8 & & \\
\hline
\end{tabular}

Table 2: Factor Loadings, mean and SD, and communalities (h2) for principal components analysis with varimax rotation on the 16 items of Preference for Lecture or Team-Based Learning Subscale 


\begin{tabular}{|c|c|c|c|c|c|c|}
\hline Item & F1 & F2 & F 3 & F 4 & $\begin{array}{c}\text { Mean } \\
(\mathrm{SD})\end{array}$ & \begin{tabular}{|c|c|c|} 
Communalities \\
$h 2$
\end{tabular} \\
\hline Q10. I am easily distracted during traditional lecture. & .839 & .118 & -.103 & -.044 & $\begin{array}{c}3.5 \\
(1.4)\end{array}$ & 0.731 \\
\hline $\begin{array}{l}\text { Q9. During traditional lecture, I often find myself thinking of non- } \\
\text { related things. }\end{array}$ & .817 & .019 & -.013 & -.106 & \begin{tabular}{c|c}
3.5 \\
$(1.4)$
\end{tabular} & 0.679 \\
\hline $\begin{array}{l}\text { Q12. I am more likely to fall asleep during lecture than during classes } \\
\text { that use team-based learning activities. }\end{array}$ & \begin{tabular}{|l|}
.724 \\
\end{tabular} & \begin{tabular}{|l|}
.151 \\
\end{tabular} & -.112 & .071 & $\begin{array}{c}3.4 \\
(1.3)\end{array}$ & 0.565 \\
\hline $\begin{array}{l}\text { Q24. After listening to lecture, I find it difficult to remember what the } \\
\text { instructor talked about during class. }\end{array}$ & .580 & \begin{tabular}{|l|}
.082 \\
\end{tabular} & .161 & -.225 & $\begin{array}{c}3.0 \\
(3.1) \\
\end{array}$ & 0.419 \\
\hline $\begin{array}{l}\text { Q19. I remember information longer when I go over it with team } \\
\text { members during the GRATS used in team-based learning. }\end{array}$ & \begin{tabular}{|l}
.039 \\
\end{tabular} & \begin{tabular}{|l|}
.715 \\
\end{tabular} & \begin{tabular}{|l|}
-.077 \\
\end{tabular} & .023 & $\begin{array}{c}3.6 \\
(1.2)\end{array}$ & 0.520 \\
\hline $\begin{array}{l}\text { Q20. I remember material better after the application exercises used } \\
\text { in team-based learning. }\end{array}$ & -.001 & .714 & -.175 & -.149 & $\begin{array}{c}3.1 \\
(1.3)\end{array}$ & 0.562 \\
\hline Q17. Team-based learning activities help me recall past information. & .225 & .705 & -.308 & .108 & $\begin{array}{c}3.5 \\
(1.2)\end{array}$ & 0.655 \\
\hline Q15. I easily remember what I learn when working & .349 & .598 & -.236 & .105 & $\begin{array}{c}3.0 \\
(1.4) \\
\end{array}$ & 0.546 \\
\hline $\begin{array}{l}\text { Q23. I do better on exams when we used team-based learning to cover } \\
\text { the material. }\end{array}$ & .132 & .567 & .236 & -.521 & $\begin{array}{c}3.0 \\
(1.2) \\
\end{array}$ & 0.666 \\
\hline $\begin{array}{l}\text { Q22. After working with my team members, I find it difficult to } \\
\text { remember what we talked about during class. }\end{array}$ & .004 & -.226 & .728 & .112 & $\begin{array}{c}2.8 \\
(1.0)\end{array}$ & 0.594 \\
\hline $\begin{array}{l}\text { Q14. I talk about non-related things during team-based learning } \\
\text { activities. }\end{array}$ & .047 & .014 & .725 & .113 & $\begin{array}{c}2.6 \\
(1.2)\end{array}$ & 0.541 \\
\hline Q13. I get bored during team-based learning activities. & -.270 & -.160 & .711 & .001 & $\begin{array}{c}2.7 \\
(1.3)\end{array}$ & 0.604 \\
\hline Q11. I am easily distracted during team-based learning activities. & .033 & -.157 & .527 & .165 & $\begin{array}{c}3.2 \\
(1.4) \\
\end{array}$ & 0.331 \\
\hline $\begin{array}{l}\text { Q18. It is easier to study for tests when the instructor has lectured } \\
\text { over the material. }\end{array}$ & .046 & -.051 & .232 & .790 & $\begin{array}{c}3.9 \\
(1.1) \\
\end{array}$ & 0.682 \\
\hline Q21. I can easily remember material from lecture. & -.408 & .029 & .208 & .611 & $\begin{array}{c}3.5 \\
(1.3) \\
\end{array}$ & 0.584 \\
\hline Q16. I remember material better when the instructor lectures about it. & -.148 & .418 & .368 & .507 & $\begin{array}{c}3.3 \\
(1.4) \\
\end{array}$ & 0.589 \\
\hline \begin{tabular}{|l} 
Eigenvalue \\
\end{tabular} & 3.9 & 2.1 & 2.0 & 1.3 & & \\
\hline$\%$ of variance & 24.6 & 12.8 & \begin{tabular}{|l|}
12.7 \\
\end{tabular} & 7.9 & & \\
\hline
\end{tabular}

Table 3: Factor Loadings, mean and SD, and communalities (h2) for principal components analysis with varimax rotation on the 9 items of students satisfaction

\begin{tabular}{|c|c|c|c|c|}
\hline Item & $\begin{array}{c}\text { Factor } \\
1\end{array}$ & $\begin{array}{l}\text { Factor } \\
2\end{array}$ & $\begin{array}{l}\text { Mean } \\
\text { (SD) }\end{array}$ & \begin{tabular}{|c|c|c|} 
Communalities \\
$h 2$
\end{tabular} \\
\hline Q32. I have a positive attitude toward team-based learning activities. & .861 & -.174 & $3.4(1.3)$ & 0.771 \\
\hline Q29. Team-based learning activities are fun. & .789 & -.122 & $3.7(1.2)$ & 0.637 \\
\hline $\begin{array}{l}\text { Q27. I think team-based learning activities are an effective approach to } \\
\text { learning. }\end{array}$ & .788 & -.230 & $3.7(1.3)$ & 0.675 \\
\hline Q25. I enjoy team-based learning activities. & .778 & -.160 & $3.3(1.4)$ & 0.631 \\
\hline Q26. I learn better in a team setting. & .724 & -.312 & $3.6(1.2)$ & 0.621 \\
\hline Q31. I think team-based learning helped me improve my grade. & .717 & .101 & $3.2(1.3)$ & 0.524 \\
\hline Q33. I have had a good experience with team-based learning. & .445 & .130 & $4.1(1.0)$ & 0.215 \\
\hline Q28. I do not like to work in teams. & -.025 & .812 & $3.0(1.5)$ & 0.660 \\
\hline Q30. Team-based learning activities are a waste of time. & -.124 & .779 & $3.1(1.3)$ & 0.622 \\
\hline
\end{tabular}


Table 4: Comparison of TBL student assessment instrument total score and sub-scale scores by the different academic rears

\begin{tabular}{|c|c|c|c|c|c|c|c|c|c|c|c|}
\hline \multirow[b]{2}{*}{$\begin{array}{l}\text { Academic } \\
\text { Year }\end{array}$} & \multicolumn{3}{|c|}{ Accountability } & \multicolumn{3}{|c|}{$\begin{array}{l}\text { Preferences (TBL vs. } \\
\text { Lecture) }\end{array}$} & \multicolumn{3}{|c|}{ Students' satisfaction } & \multicolumn{2}{|c|}{ Total } \\
\hline & Range & Mean(SD) & $\begin{array}{c}\mathrm{P} . \\
\text { value }\end{array}$ & Range & Mean(SD) & $\begin{array}{c}\mathrm{P} . \\
\text { value }\end{array}$ & Range & Mean(SD) & $\begin{array}{c}\mathrm{P} . \\
\text { value }\end{array}$ & Range & Mean(SD) \\
\hline $\begin{array}{l}\text { Year two } \\
(\mathrm{n}=42)\end{array}$ & $12-37$ & $28.1(4.9)$ & 0.0 .49 & $23-63$ & $51.1(6.1)$ & 0.001 & $15-40$ & $31.0(5.6)$ & $<0.001$ & $\begin{array}{l}50- \\
139\end{array}$ & $\begin{array}{l}110.2 \\
(13.5)\end{array}$ \\
\hline $\begin{array}{l}\text { Year } \\
\text { three } \\
(\mathrm{n}=36) \\
\end{array}$ & $12-33$ & $27.1(6.1)$ & & $37-63$ & 49.1.(6.5) & & $21-38$ & $28.4(5.2)$ & & $\begin{array}{l}83- \\
133\end{array}$ & $\begin{array}{l}104.6 \\
(13.4)\end{array}$ \\
\hline $\begin{array}{l}\text { Year } \\
\text { four } \\
(n=31)\end{array}$ & $17-39$ & $30.4(5.4)$ & & $38-74$ & $55.6(8.2)$ & & $19-44$ & $35.8(6.2)$ & & $\begin{array}{l}86- \\
147\end{array}$ & $\begin{array}{l}121.7 \\
(14.9)\end{array}$ \\
\hline $\begin{array}{l}\text { Total } \\
(\mathrm{n}=109)\end{array}$ & $12-39$ & $28.4(5.5)$ & & $23-74$ & $51.7(7.3)$ & & $15-44$ & $\begin{array}{l}31.5 \\
(6.3)\end{array}$ & & $\begin{array}{l}50- \\
147\end{array}$ & $\begin{array}{l}111.6 \\
(15.4)\end{array}$ \\
\hline
\end{tabular}

\section{Supplementary Files}

This is a list of supplementary files associated with this preprint. Click to download.

- STROBEchecklistcrosssectionalCopy.doc 